\title{
Coronalidia, gênero novo de Neocoelidiinae (Hemiptera, Cicadellidae) do Equador ${ }^{1}$
}

\author{
Ana Paula Marques-Costa ${ }^{2} \&$ Rodney Ramiro Cavichioli ${ }^{2}$
}

${ }^{1}$ Contribuição número 1672 do Departamento de Zoologia, Universidade Federal do Paraná.

${ }^{2}$ Programa de Pós-Graduação em Entomologia, Departamento de Zoologia, Universidade Federal do Paraná. Caixa Postal 19020, 81531-980 Curitiba, Paraná, Brasil. apcm@ufpr.br; cavich@ufpr.br

\begin{abstract}
Coronalidia, new genus of Neocoelidiinae (Hemiptera, Cicadellidae) from Ecuador. A new genus of Neocoelidiinae, Coronalidia gen. nov., and two new species, Coronalidia pictapennis sp. nov. and Coronalidia sagittata sp. nov., are described from Ecuador. Coronalidia gen. nov. can be distinguished from other genera of Neocoelidiinae by the long coronal suture, almost reaching the anterior margin of crown, its elongated process in the base of anal tube, and ventral margin of the aedeagus with denticles. The females of this genus are unknown. Illustrations and the known geographical distribution of the studied species are given.
\end{abstract}

KEYWORDS. Geographical distribution; morphology; new species; taxonomy.

RESUMO. Coronalidia, gênero novo de Neocoelidiinae (Hemiptera, Cicadellidae) do Equador. Um gênero novo de Neocoelidiinae, Coronalidia gen. nov., e duas espécies novas, Coronalidia pictapennis sp. nov. e Coronalidia sagittata sp. nov., são descritos. Coronalidia gen. nov. pode ser separado dos demais gêneros de Neocoelidiinae pela longa sutura coronal, quase atingindo a margem anterior da coroa, pela presença de um processo alongado na base do tubo anal e margem ventral do edeago com dentículos. As fêmeas deste gênero não são conhecidas. Ilustrações e a distribuição geográfica conhecida das espécies estudadas são fornecidas.

PALAVRAS-CHAVE. Distribuição geográfica; espécies novas; morfologia; taxonomia.

Neocoelidiinae compreende uma única tribo, Neocoelidiini, atualmente com 169 espécies em 30 gêneros, incluindo as espécies de Coronalidia (Marques-Costa \& Cavichioli 2007 a, b, c, d). A subfamília é principalmente neotropical, havendo apenas quatro gêneros com registro para a Região Neártica (Nielson \& Knight 2000). A subfamília inclui cigarrinhas de tamanho pequeno a grande $(3,0-14,0 \mathrm{~mm})$, de coloração geral normalmente em tons pálidos, que podem ser identificadas pelo seguinte conjunto de caracteres: cabeça projetada anteriormente, freqüentemente com carena marginal; coroa elevada e achatada entre os olhos; ocelos na margem anterior da cabeça ou muito próximos a esta; suturas frontogenais estendendo-se ou não até os ocelos; antenas extremamente longas, com escapo e pedicelo bem desenvolvidos; clípeo com ou sem intumescimento mediano ou túberculo; mesotórax freqüentemente bem desenvolvido, a pleura estendendo-se até a região do esterno, dando aos neocelidiíneos um aspecto intumescido ventralmente; venação da asa anterior geralmente indistinta, exceto apicalmente e $\mathrm{R}_{4+5}$ e $\mathrm{M}_{1+2}$ da asa posterior geralmente confluentes pré-apicalmente.

Este trabalho inclui, a descrição de um gênero novo de Neocoelidiinae, Coronalidia gen. nov., e de duas espécies novas, $C$. pictapennis sp. nov. e $C$. sagittata $\mathbf{s p . ~ n o v . , ~ a m b a s ~}$ provenientes do Equador.

\section{MATERIALE MÉTODOS}

O material estudado pertence ao United States National Museum (USNM), Washington D.C., Estados Unidos.
Para a análise das estruturas da genitália, seguiu-se a metodologia adotada por Marques-Costa \& Cavichioli (2006), exceto pelo que segue: a asa anterior foi ilustrada diretamente a partir dos espécimes-tipo, evitando assim, a remoção das asas dos holótipos. Os espécimes foram identificados e descritos com o auxílio de microscópio estereoscópico da marca Wild modelo M3Z. Este mesmo equipamento foi utilizado para confecção das ilustrações de morfologia externa, e os desenhos de genitália foram feitos com o auxílio de um microscópio óptico Zeiss, ambos acoplados com câmara clara. Os tipos foram fotografados em vista dorsal e lateral, utilizandose um computador com software de automontagem, conectado a um microscópio estereoscópico Wild M400 com câmera digital JVC KY-F70 acoplada.

A terminologia adotada segue principalmente os trabalhos de Kramer (1964) e Young $(1968,1977,1986)$, exceto para as estruturas da cabeça, cuja terminologia segue o trabalho de Hamilton (1981), conforme sugerido por Mejdalani (1998); a venação das asas segue Comstock and Needham $(1898,1899)$, como sugerido por Oman (1949) e a posição das cerdas da tíbia posterior segue Rakitov (1998).

\section{Coronalidia gen. nov.}

(Figs. 1-29)

Espécie-tipo: Coronalidia pictapennis sp. nov.

Diagnose. Sutura coronal longa e evidente, quase atingindo a margem anterior da coroa (Figs. 1 e 14); carena transversal entre coroa e fronte; genitália masculina: pigóforo com dente 
ventral medianamente, ápice estreitado e pontiagudo, bifurcado ou não, e lobos internos pré-apicais cobertos por dentículos (Figs. 5-6, 18-19); placas subgenitais quase inteiramente fusionadas entre si, exceto no ápice (Figs. 7 e 20); edeago robusto, com par de processos pré-apicais laterais pequenos e margem ventral do terço médio com dentículos (Figs. 10-11, 23-24); tubo anal longo e membranoso, com processo basal de formato variável (Figs. 5-6, 12-13, 18-19 e 25).

Descrição. Em vista dorsal, corpo pequeno, aproximadamente cilíndrico, estreitado posteriormente, não achatado dorso-ventralmente.

Cabeça. Coroa, em vista dorsal, aproximadamente pentagonal, pouco projetada anteriormente, tão larga quanto longa (Figs. 1 e 14); margem anterior arqueada e angulada, com carena transversal na transição entre coroa e fronte; margens laterais, adjacentes aos olhos compostos, elevadas e fortemente carenadas (Figs. 3 e 16); superfície côncava, lisa, sem estrias, com máculas coronais visíveis; sutura coronal distinta, muito longa, estendendo-se em quase todo comprimento da coroa, da base à porção pré-apical, não atingindo a margem anterior (Figs. 1 e 14); forte intumescimento ao longo da sutura coronal; ocelos pequenos, na transição entre coroa e fronte, acima dos lobos supraantenais, mais próximos aos olhos compostos que da linha mediana, não visíveis em vista dorsal; lobos supra-antenais, em vista lateral, oblíquos e fortemente carenados; flagelos antenais tão longos quanto o comprimento do corpo, ultrapassando a metade basal das asas anteriores; fronte com perfil convexo, sem intumescimento central na base, não carenada; impressões musculares levemente visíveis (Figs. 2-3, 15-16); suturas frontogenais atingindo os ocelos; margem apical das placas maxilares aproximadamente na mesma altura do ápice do clípeo; loros em formato de meia-lua, margens inferiores não atingindo o ápice do clípeo; genas não cobrindo completamente os proepisternos, estes visíveis em vista frontal apenas pelo ápice; sutura epistomal distinta e completa, retilínea; clípeo retangular, com margens laterais paralelas e margem apical retilínea, em vista lateral, não intumescido, perfil contínuo à fronte (Figs. 2 e 15).

Tórax . Pronoto pouco mais largo que a cabeça, margens laterais arredondadas à levemente anguladas; margem posterior levemente emarginada (Figs. 1 e 14); superfície com estrias transversais; carena dorsopleural completa (Figs. 3 e 16); mesotórax, em vista ventral, moderadamente intumescido; escutelo (sensu Young, 1968) tão longo quanto sua largura máxima, com sulco distinto pré-apical. Asa anterior cerca de quatro a 4,5 vezes mais longa que sua largura máxima; com ápice arredondado, sem pontuações; sem veias elevadas, venação indistinta, exceto pela sutura claval e células apicais; quatro células apicais, todas aproximadamente retangulares; segunda e quarta células apicais com bases eqüidistantes, mais proximais da base da asa do que a terceira célula apical; terceira e quarta células apicais alargadas apicalmente; quarta célula apical quase inconspícua, pouco visível; células anteapicais indistintas; apêndice estreito restrito à primeira célula apical (Figs. 4 e 17). Asa posterior com três células apicais, $\mathrm{R}_{4+5}$ e $\mathrm{M}_{1+2}$ convergentes pré-apicalmente, fusionandose no ápice. Perna posterior com fórmula femoral $2+2+0$; tíbia com fileira PD com cerdas longas e grossas, afastadas entre si, sem cerdas intercalares, uniformemente distribuídas por todo comprimento da tíbia; fileira AD com cerdas espiniformes, longas, mais grossas que as da fileira PD, com bases proeminentes e duas ou mais microcerdas intercalares, distribuídas em todo comprimento da tíbia; fileira AV com cerdas semelhantes as da fileira PD, pouco mais curtas e finas, sem cerdas intercalares, afastadas entre si e presentes somente nos terços médio e apical da tíbia; fileira PV densamente cerdosa, com cerdas finas e curtas na base, crescentes em tamanho em direção ao ápice, presentes em todo comprimento da tíbia; tarsômero I tão longo quanto o comprimento da soma dos dois mais distais, com duas fileiras paralelas de microcerdas na superfície plantar.

Abdome. Genitália masculina com pigóforo aproximadamente retangular, com terço apical estreitado e pontiagudo, bifurcado ou não; com dente ventral medianamente e par pré-apical de lobos internos de tamanho variável, coberto por dentículos (Figs. 5-6, 18-19). Valva subgenital inteiramente fusionada às placas subgenitais. Placas subgenitais quase que inteiramente fusionadas entre si, exceto no ápice, e tão longas quanto o pigóforo (Figs. 7 e 20), em vista lateral, levemente côncavas. Estilos simples, sem lobo pré-apical, com ápice esclerosado, e levemente curvado ventralmente (Figs. 8-9, 21-22). Conetivo em forma de Y (Figs 21-22). Edeago com terço apical da haste estreitado, com par pré-apical de processos laterais e margem ventral do terço médio coberta por dentículos (Figs. 10-11, 23-24). Tubo anal longo e membranoso, com processo basal de formato variável (Figs. 5-6, 12-13, 18-19e 25).

Comprimento total (corpo + asas anteriores): 5,0 - 6,0 mm.

\section{Distribuição geográfica. Equador.}

Comentários. Assemelha-se a Tozzita Kramer, 1964 pela presença de processo na base do tubo anal; pelo formato das placas subgenitais, quase que inteiramente fusionadas entre si, exceto no ápice e pelo formato dos estilos. Entretanto, pode ser separado deste gênero, pela sutura coronal longa e evidente; pelo pigóforo com ápice estreitado e pontiagudo, não achatado dorso-ventralmente em forma de espátula, e com par pré-apical de lobos internos cobertos por dentículos; edeago robusto, com par pré-apical de processos laterais e margem ventral do terço médio com dentículos.

Etimologia. O nome genérico é feminino e combina a palavra corona, do latim = coroa, com o sufixo -lidia, comum a vários gêneros de Neocoelidiinae. Faz referência à sutura coronal muito longa, estendendo-se até próximo à margem anterior da coroa, a área da sutura intumescida. 

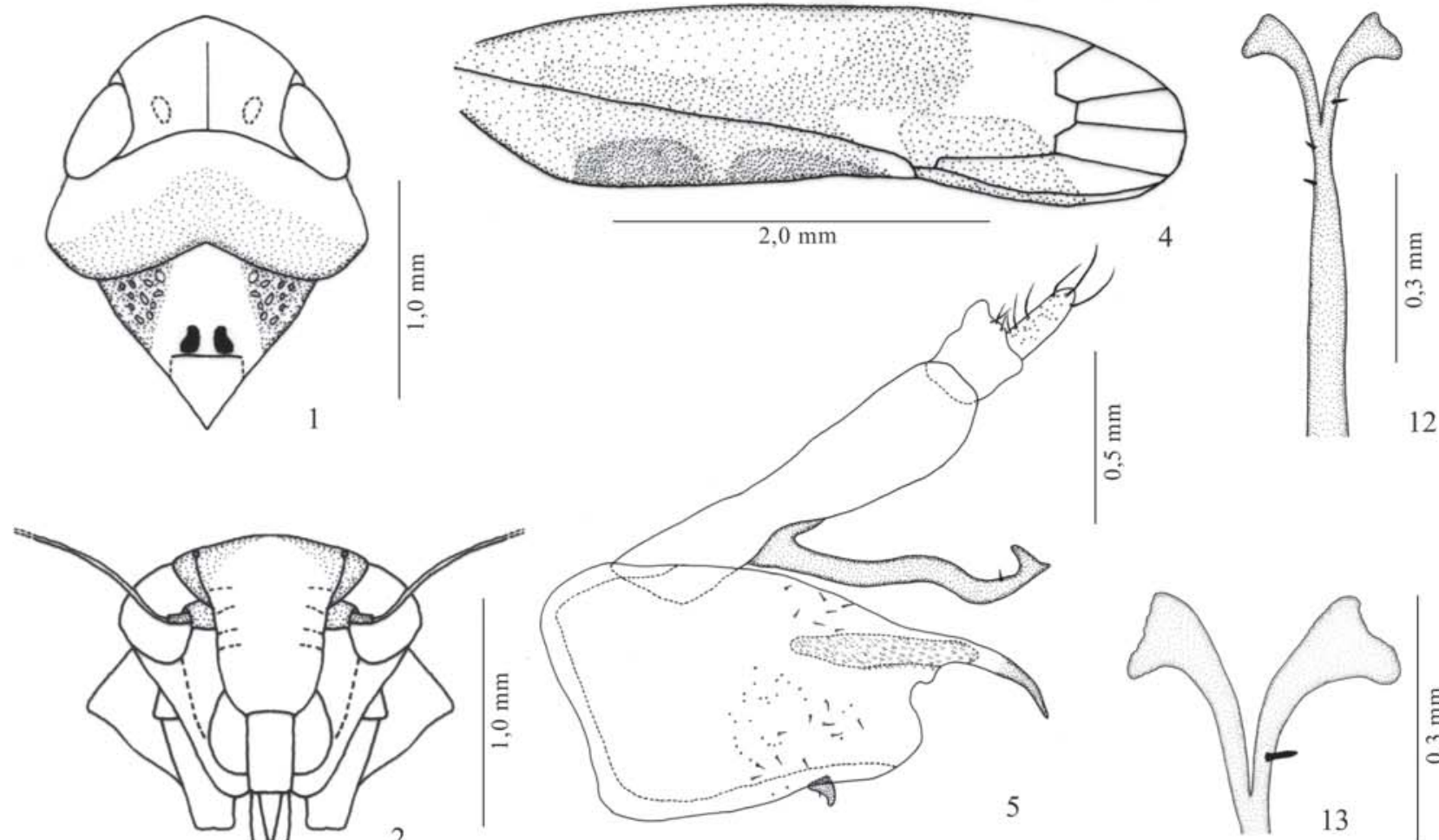

12
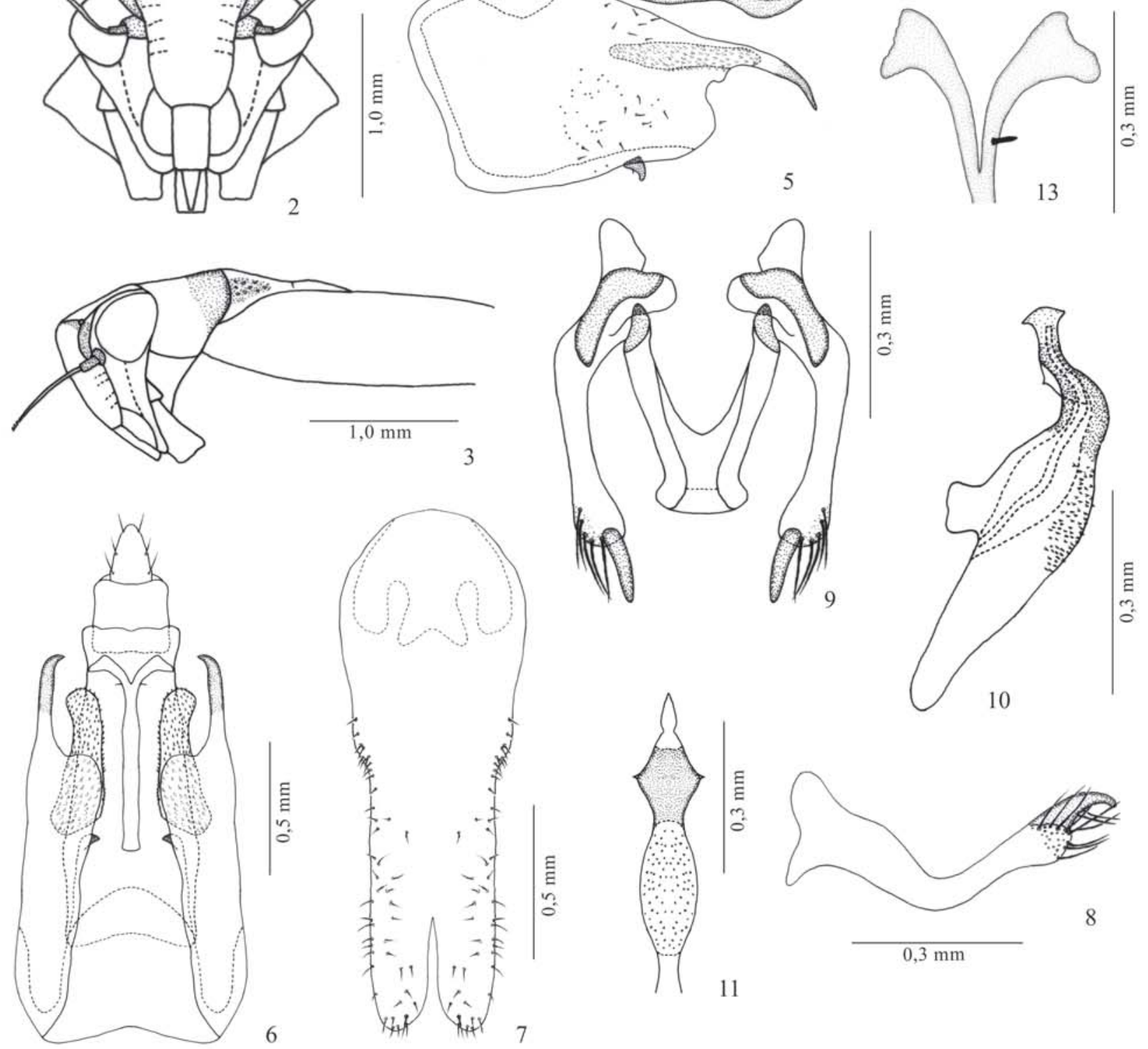

。
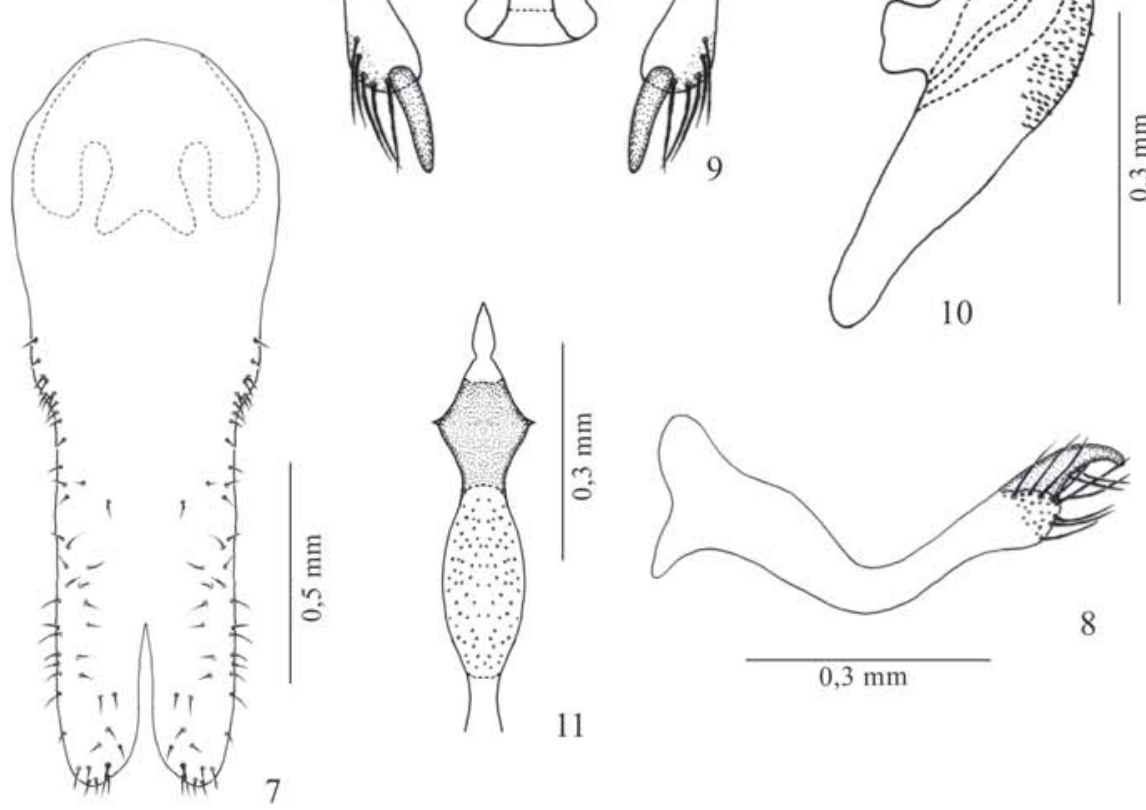

11

Figs. 1-13. Coronalidia pictapennis sp. nov., holótipo macho: 1, cabeça, pronoto e escutelo, vista dorsal; 2, cabeça, vista frontal; 3, cabeça, pronoto e escutelo, vista lateral; 4, asa anterior; 5, pigóforo e tubo anal, vista lateral; 6, pigóforo e tubo anal, vista ventral; 7, valva e placas subgenitais, vista ventral; 8, estilo, vista lateral; 9, estilos e conetivo, vista dorsal; 10, edeago, vista lateral; 11, edeago, terços médio e apical, vista ventral; 12, processo do tubo anal, vista ventral; 13, detalhe do ápice do processo do tubo anal, vista ventral. 

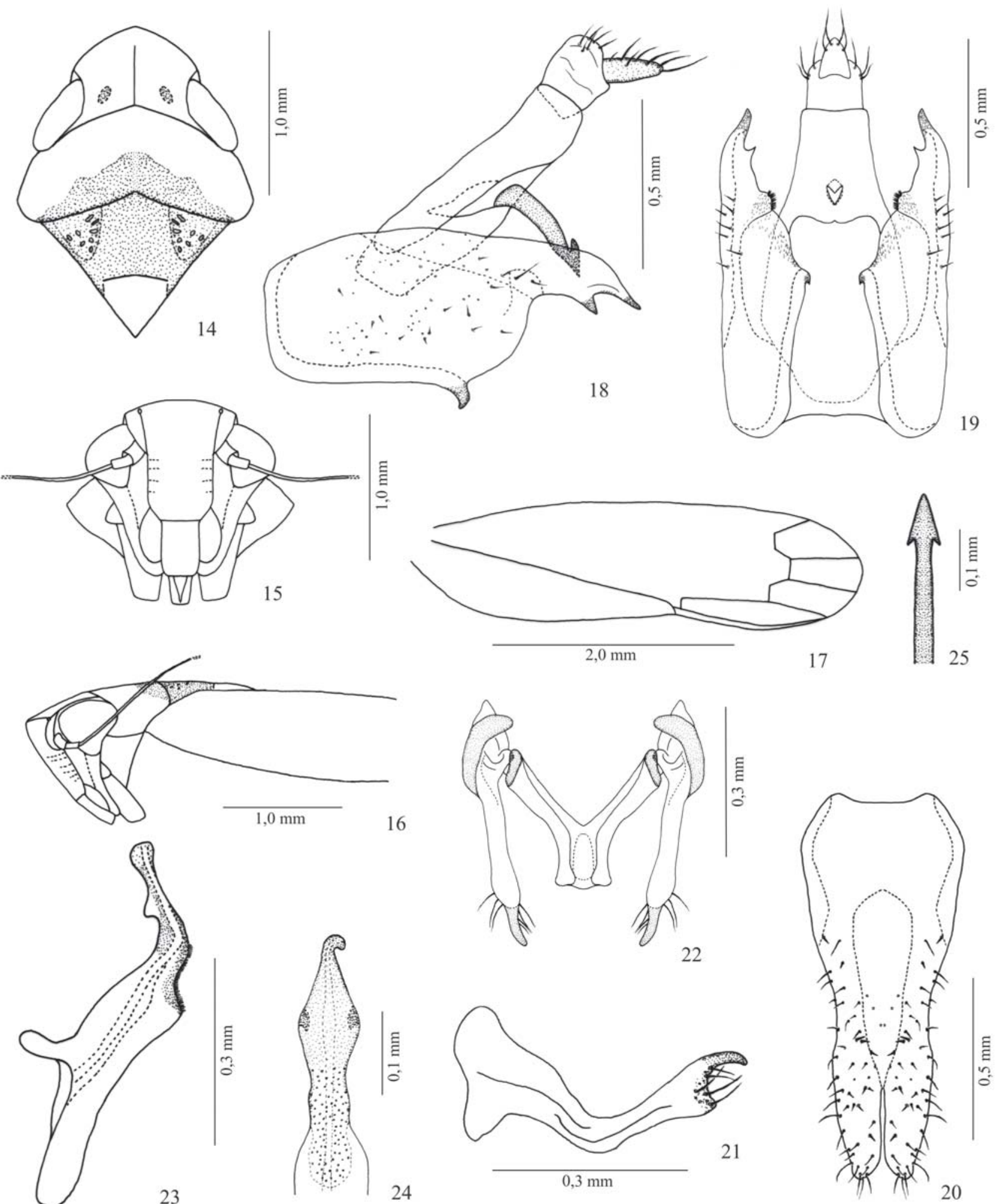

Figs. 14-25. Coronalidia sagittata sp. nov., holótipo macho: 14, cabeça, pronoto e escutelo, vista dorsal; 15, cabeça, vista frontal; 16, cabeça, pronoto e escutelo, vista lateral; 17, asa anterior; 18, pigóforo e tubo anal, vista lateral; 19, pigóforo e tubo anal, vista ventral; 20, valva e placas subgenitais, vista ventral; 21, estilo, vista lateral; 22, estilos e conetivo, vista dorsal; 23, edeago, vista lateral; 24, edeago, terços médio e apical, vista ventral; 25 , processo do tubo anal, vista dorsal. 


\section{Coronalidia pictapennis sp. nov.}

(Figs. 1-13, 26-27)

Localidade-tipo: Estácion Biológica Jatun Sacha, Napo, Equador.

Diagnose. Asa anterior com a metade basal opaca e a metade apical hialina (Fig. 4); genitália masculina: pigóforo com terço apical não bifurcado, muito afilado e pontiagudo, com ápice curvado ventralmente e par pré-apical de lobos internos grandes, não curvados para dentro (Figs. 5-6); edeago com par pré-apical de dentículos laterais e ápice membranoso, em vista lateral, em forma de seta (Figs. 10-11); tubo anal com processo basal esclerosado, com porção apical bifurcada, ramos com ápices em forma de pé (Figs. 5-6, 12-13).

Medidas (mm). Holótipo macho: comprimento total 5,65; comprimento mediano da coroa 0,56 ; distância transocular 1,32 ; distância interocular 0,68 ; comprimento mediano do pronoto 0,56; distância trans-humeral 1,52; comprimento mediano do escutelo 0,92 ; largura máxima do escutelo 1,0; comprimento da asa anterior 4,64; largura máxima da asa anterior 1,04; largura basal da fronte 0,60 ; comprimento da fronte 0,84 .

Descrição. Caracteres estruturais como na descrição genérica. Comprimento mediano da coroa aproximadamente igual à distância interocular e metade da distância transocular; fronte com comprimento aproximadamente 1,5 vezes sua largura basal; distância trans-humeral aproximadamente igual à distância transocular; comprimento mediano do pronoto cerca de um terço da distância trans-humeral; asa anterior com comprimento aproximadamente 4,5 vezes sua largura máxima. Genitália masculina com pigóforo, em vista lateral, com terços basal e médio alargados e terço apical abruptamente estreitado, afilado e pontiagudo, não bifurcado, com ápice esclerosado e curvado ventralmente; com grande par pré-apical de lobos internos, não curvados para dentro; cerdas presentes na metade apical (Figs. 5-6). Placas subgenitais aproximadamente triangulares, com ápices arredondados, alargadas basalmente, estreitando-se na metade apical; cada placa com comprimento aproximadamente cinco vezes sua largura máxima; cerdas distribuídas nos terços médio e apical (Fig. 7). Estilos moderadamente longos e afilados, com cerdas longas e finas no quarto apical e margens sem ondulações (Figs. 8-9). Conetivo com porção central alargada, cerca de metade do comprimento dos estilos, articulado à base do edeago (Fig. 9). Edeago, em vista lateral, alargado nos terços basal e médio, estreitando-se em direção ao ápice; base com prolongamento ventral engrossado e apódema dorsal curto aproximadamente quadrangular; haste com terço apical curvado dorsalmente e anteriormente e porção pré-apical esclerotinizada, com par de pequenos dentículos laterais; ápice membranoso, em vista lateral, em forma de seta; gonóporo apical (Figs. 10-11). Tubo anal com processo basal longo e esclerosado, com porção apical bifurcada, ramos com ápices em forma de pé (Figs. 5-6, 12-13) e um ou dois minúsculos espinhos na porção pré-apical do processo (Figs. 12-13).
Fêmea. Desconhecida.

Coloração geral. Amarelo-palha com manchas em tons esbranquiçados, amarelados e marrons, principalmente nas asas anteriores. Cabeça, em vista frontal, inteiramente amarelopalha, sem manchas, exceto na base da fronte; antenas com escapo e pedicelo levemente mais escurecidos, manchados de marrom-claro (Fig. 2); coroa amarelada, sem manchas. Pronoto amarelo, margem posterior manchada de marromescuro. Escutelo quase inteiramente amarelo-palha a esbranquiçado, com par de manchas aproximadamente triangulares marrom-escuras e esculturadas, próximas aos ângulos laterais; um par de pequenas manchas marrom-escuras a pretas anteriores ao sulco pré-apical (Fig. 1). Asa anterior opaca na metade basal, com coloração esbranquiçada na base do clavo e próximo à margem costal; restante do clavo com grande mancha amarelada a bege cobrindo quase toda sua extensão e alongando-se acima da sutura claval, estendendose até próximo à margem costal na porção pré-apical; duas manchas marrom-claras grandes na margem anal do clavo; metade apical da asa hialina, enfuscada de castanho na primeira célula apical, apêndice e ápice da célula braquial (Fig. 4). Asa posterior hialina, sem coloração distinta, com veias amareladas. Pernas amarelo-palha com cerdas da mesma cor.

Material examinado. Holótipo macho (USNM), etiquetado: "ECUADOR, Napo, Estácion Biológica Jatun Sacha, 02.viii.1989, at light, P.H. Freytag and T. Myers leg."

Condição do holótipo. Tórax colado ventralmente em triângulo; flagelo antenal direito com terço apical colado no triângulo e o esquerdo quebrado somente no ápice; todas as pernas e asas em perfeito estado de conservação; abdome dissecado.

Etimologia. Do latim, picta =pintada e pennis = asa, referindo-se à coloração da asa anterior, que possui os terços basal e médio opacos e com manchas, e apenas o terço apical hialino.

\section{Coronalidia sagittata $\mathbf{s p . ~ n o v . ~}$}

(Figs. 14-25, 28-29)

Localidade-tipo: Estácion Biológica Jatun Sacha, Napo, Equador.

Diagnose. Asa anterior inteiramente hialina (Fig. 17); genitália masculina: pigóforo com terço apical bifurcado, ramo dorsal maior, estreitado, pontiagudo e curvado ventralmente, ramo ventral menor, em forma de dente e par pré-apical de lobos internos pequenos e curvados para dentro (Figs. 1819); edeago com par pré-apical de processos laterais pequenos e arredondados e ápice membranoso, em vista lateral, aproximadamente arredondado a truncado (Figs. 23-24); tubo anal com processo basal esclerosado, com porção apical em forma de seta, não bifurcada (Figs. 18-19 e 25). 

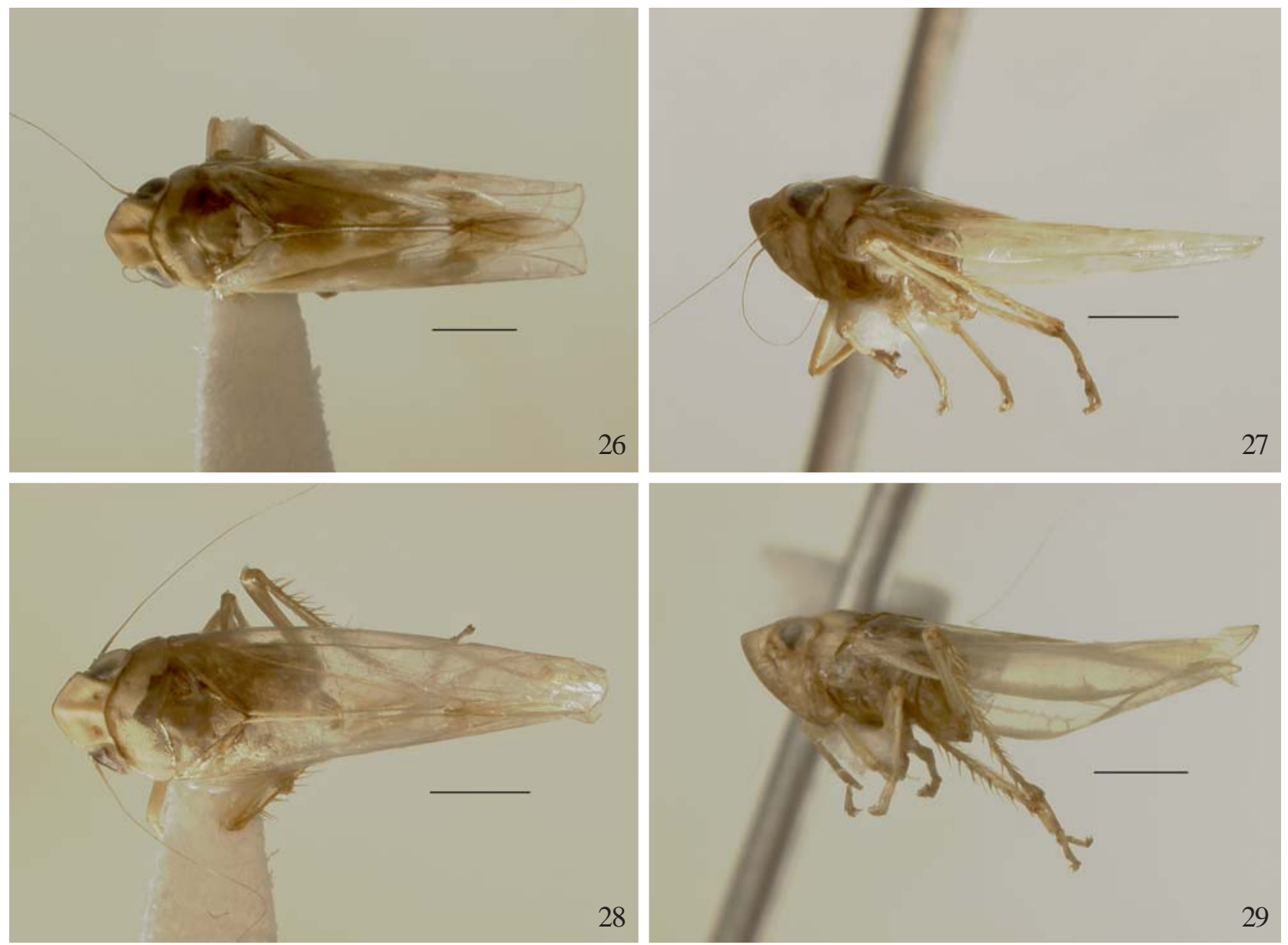

Figs. 26-29. Holótipos machos, vistas dorsal e lateral: 26-27, Coronalidia pictapennis sp. nov.; 28-29, Coronalidia sagittata sp. nov. Escalas = $1,0 \mathrm{~mm}$.

Medidas (mm). Holótipo macho: comprimento total 5,45; comprimento mediano da coroa 0,56 ; distância transocular 1,28 ; distância interocular 0,60 ; comprimento mediano do pronoto 0,56; distância trans-humeral 1,48; comprimento mediano do escutelo 0,92; largura máxima do escutelo 1,0; comprimento da asa anterior 4,34; largura máxima da asa anterior 1,08; largura basal da fronte 0,52 ; comprimento da fronte 0,84 .

Descrição. Caracteres estruturais como na descrição genérica. Comprimento mediano da coroa aproximadamente igual à distância interocular e metade da distância transocular; fronte com comprimento aproximadamente 1,5 vezes sua largura basal; distância trans-humeral aproximadamente igual à distância transocular; comprimento mediano do pronoto cerca de um terço da distância trans-humeral; asa anterior com comprimento aproximadamente quatro vezes sua largura máxima. Genitália masculina com pigóforo, em vista lateral, com terços basal e médio alargados e terço apical estreitado, com ápice bifurcado, ramo dorsal maior, estreitado, pontiagudo e curvado ventralmente, ramo ventral menor, em forma de dente, ambos com ápices esclerosados; com par pré-apical de lobos internos pequenos e curvados para dentro; cerdas presentes nos terços basal e médio, as do terço médio mais longas (Figs. 18-19). Placas subgenitais aproximadamente triangulares, com ápices arredondados, alargadas basalmente, estreitando-se na metade apical; cada placa com comprimento aproximadamente cinco vezes sua largura máxima; cerdas distribuídas nos terços médio e apical (Fig. 20). Estilos moderadamente longos e afilados, com cerdas longas e finas no quarto apical e margens sem ondulações (Figs. 21-22). Conetivo com porção central alargada, cerca de metade do comprimento dos estilos, articulado à base do edeago (Fig. 22). Edeago, em vista lateral, alargado nos terços basal e médio, estreitando-se em direção ao ápice; base com prolongamento ventral engrossado e apódema dorsal curto e estreito, aproximadamente arredondado; haste com terço apical curvado dorsalmente e anteriormente e porção pré-apical esclerosada, com par de pequenos processos laterais arredondados; ápice membranoso, em vista lateral, aproximadamente arredondado a truncado; gonóporo apical (Figs. 23 e 24). Tubo anal com processo basal esclerosado, moderadamente longo, com porção apical em forma de seta, não bifurcada, e sem espinhos na porção pré-apical (Figs. 18-19 e 25). 
Fêmea. Desconhecida.

Coloração geral. Amarelo-palha. Cabeça, em vista frontal, inteiramente amarelo-palha, sem manchas distintas (Fig. 15). Coroa amarelo-palha, máculas coronais manchadas de marrom. Pronoto quase que inteiramente amarelo-palha, margem posterior manchada de marrom-escuro. Escutelo marromescuro com ápice amarelo-palha e par de manchas laterais aproximadamente triangulares marrons com esculturações (Fig. 14). Asa anterior hialina, amarelada a castanho-clara, com veias amarelas e sem manchas, apenas base do apêndice levemente enfuscada de castanho (Fig. 17). Asa posterior hialina, sem coloração distinta, com veias amareladas. Pernas amarelopalha com cerdas da mesma cor.

Material examinado. Holótipo macho (USNM), etiquetado: "ECUADOR, Napo, Estácion Biológica Jatun Sacha, 30.vii.1989, at light, P.H. Freytag and T. Myers leg."

Condição do holótipo. Tórax colado ventralmente em triângulo entomológico; flagelos antenais, pernas e asas posteriores em perfeito estado de conservação; asas anteriores parcialmente quebradas apicalmente; abdome dissecado.

Etimologia. Do latim, sagitta $=$ flecha, seta, $a t a=$ sufixo de posse, portanto sagittata, com formato de seta, referindo-se ao formato do processo basal do tubo anal.

Agradecimentos. Ao Dr. Paul H. Freytag (University of Kentucky, Estados Unidos) pelo empréstimo dos espécimes, ao Dr. Thomas J. Henry e Michele A. Touchet (técnica do setor de Entomologia) pela orientação e auxílio durante o estágio de Doutorado Sanduíche realizado no USNM, à Coordenação de Aperfeiçoamento de Pessoal de Nível Superior (CAPES) pela bolsa de Doutorado Sanduíche concedida à primeira autora e ao Conselho Nacional de Desenvolvimento Científico e Tecnológico (CNPq) pela bolsa de produtividade concedida ao segundo autor.

\section{REFERÊNCIAS}

Comstock, J. H. \& J. G. Needham. 1898. The wings of insects. American Naturalist 32: 43-48, 81-89, 231-257, 335-340, 413-424, 561-565, 768-777, 903-911.
Comstock, J. H. \& J. G. Needham. 1899. The wings of insects. American Naturalist 33: 117-126, 573-582, 845-860.

Hamilton, K. G. A. 1981. Morphology and evolution of the rhynchotan head (Insecta: Hemiptera, Homoptera). Canadian Entomologist 113: 953-974.

Kramer, J. P. 1964. A generic revision of the leafhopper subfamily Neocoelidiinae (Homoptera: Cicadellidae). Proceedings of the United States National Museum 115: 259-287.

Marques-Costa, A. P. \& R. R. Cavichioli. 2006. Revisão taxonômica, análise cladística e descrição de espécies novas de Aglaenita Spinola (Hemiptera, Cicadellidae, Neocoelidiinae). Revista Brasileira de Entomologia 50: 355-378.

Marques-Costa, A. P. \& R. R. Cavichioli. 2007a. Descrição de um novo gênero amazônico de Neocoelidiinae (Hemiptera, Auchenorrhyncha, Cicadellidae). Revista Brasileira de Zoologia 24: $228-232$.

Marques-Costa, A. P. \& R. R. Cavichioli. 2007b. Neocoelindroma, gênero novo de Neocoelidiinae (Hemiptera, Auchenorrhyncha, Cicadellidae) da Região Neotropical. Revista Brasileira de Zoologia 24: 233-237.

Marques-Costa, A. P. \& R. R. Cavichioli. 2007c. Descrição de um gênero novo e cinco espécies novas de Neocoelidiinae (Hemiptera, Auchenorrhyncha, Cicadellidae). Revista Brasileira de Entomologia 51: 176-186.

Marques-Costa, A. P. \& R. R. Cavichioli. 2007d. Revision of Coelana, Kramer, 1964 (Hemiptera, Cicadellidae, Neocoelidiinae) and taxonomic notes on the genus. Zootaxa 1547: 33-42.

Mejdalani, G. 1998. Morfologia externa dos Cicadellinae (Homoptera: Cicadellidae): comparação entre Versigonalia ruficauda (Walker) (Cicadellini) e Tretogonia cribrata (Melichar) (Proconiini), com notas sobre outras espécies e análise da terminologia. Revista Brasileira de Zoologia 15: 451-544.

Nielson, M. W. \& W. J. Knight. 2000. Distributional patterns and possible origin of leafhoppers. (Homoptera, Cicadellidae). Revista Brasileira de Zoologia 17: 81-156.

Oman, P. W. 1949. The Nearctic leafhoppers (Homoptera: Cicadellidae). A generic classification and check list. Memoirs of the Entomological Society of Washington 3: 1-253.

Rakitov, R. A. 1998. On differentiation of cicadellid leg chaetotaxy. Russian Entomological Journal 6: 7-27.

Young, D. A. 1968. Taxonomic study of the Cicadellinae (Homoptera, Cicadellidae). Part 1. Proconiini. Bulletin of the United States National Museum 261: 1-287.

Young, D. A. 1977. Taxonomic study of the Cicadellinae (Homoptera: Cicadellidae). Part 2. New World Cicadellini and genus Cicadella. Bulletin of the North Carolina Agricultural Experiment Station 239: VI+1135 p.

Young, D. A. 1986. Taxonomic study of the Cicadellinae (Homoptera: Cicadellidae). Part 3. Old World Cicadellini. Bulletin of the North Carolina Agricultural Experiment Station 281: 1-639.

Recebido em 17/11/2006; aceito em 16/04/2007 